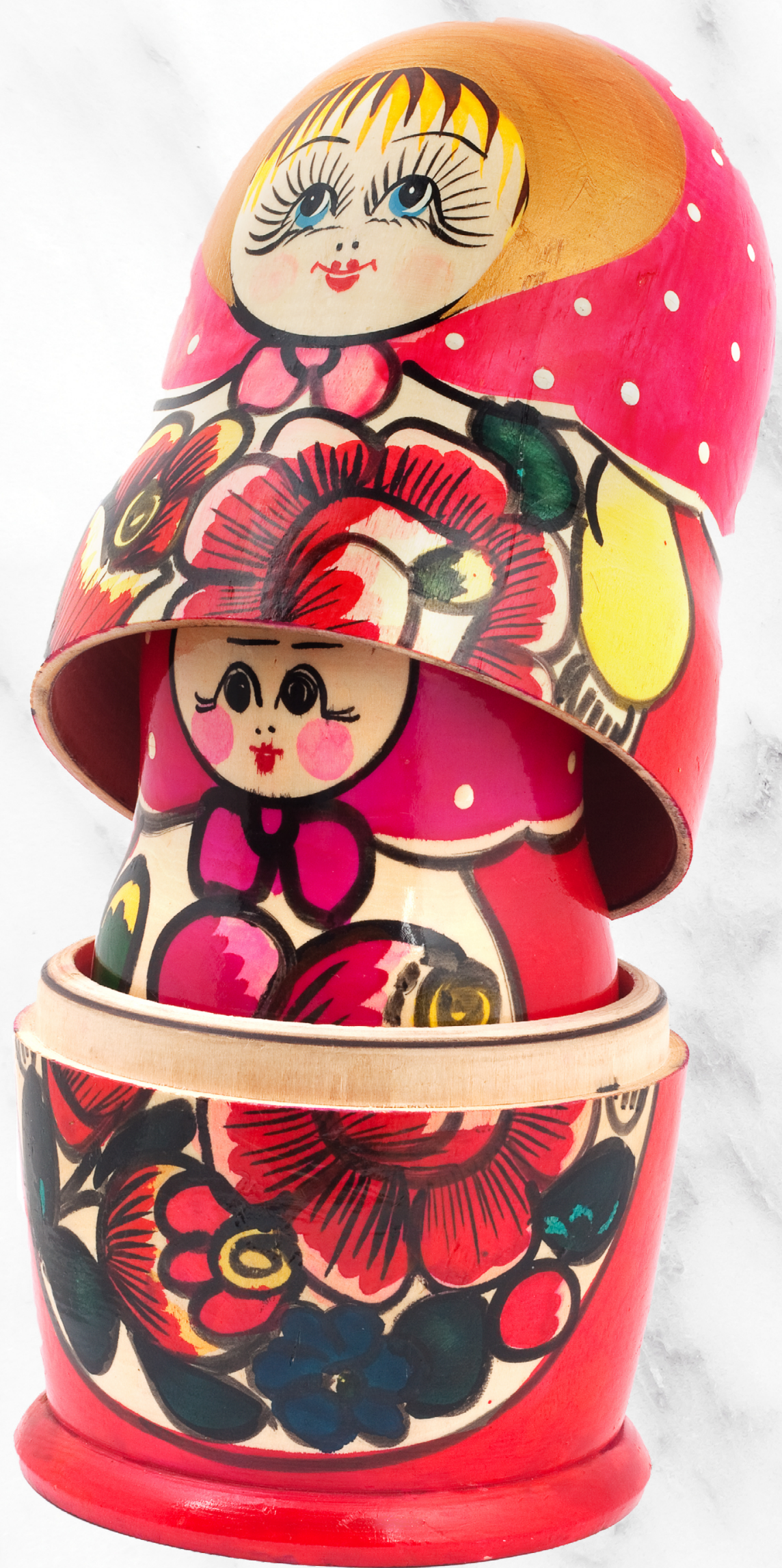




\section{O POTENCIAL DA LOJA DENTRO DA LOJA}

| POR LEANDRO ULISSES DE MORAES E BENJAMIN ROSENTHAL

\section{O sistema shop-in-shop desponta como uma alternativa de menor custo para fortalecer marcas, expor melhor os produtos e expandir clientes e vendas.}

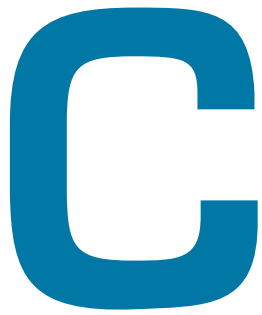

om perspectivas de aumentar as vendas no pós-pandemia, redes de varejo dos Estados Unidos têm anunciado parcerias para ter, em suas lojas, espaços de fabricantes e varejistas. A Target, por exemplo, abrigará pontos de venda da rede de lojas de produtos de beleza Ulta Beauty, enquanto a Kohl's terá ambientes da Sephora e expandirá os da Adidas. O modelo, conhecido como shop-in-shop (uma loja dentro da outra), é mais disseminado no mercado norte-americano do que no brasileiro, mas tem potencial para crescer no país, pois desponta como uma alternativa de menor custo para dar visibilidade a marcas e expandir o público consumidor e o fluxo de vendas de ambas as partes.

No Brasil, é a possibilidade de expansão a custos mais baixos que vem impulsionando a adoção do sistema shop-in-shop, pois há possibilidade de atrair maior fluxo de clientes e, ao mesmo tempo, dividir custos fixos de espaço, energia elétrica, estacionamento, segurança, limpeza, entre outros. Exemplos são a Love Brands, que tem no mesmo ambiente os pontos das marcas Balonè Acessórios, Imaginarium, Chilli Beans e Puket, e iniciativas no sistema de franquias, como é o caso do shop-in-shop da marca Tostex nas franquias do Giraffas e da pizzaria Domino's Pizza nos pontos de venda do Spoleto.

\author{
Quando há sinergia entre \\ as partes - com norte \\ estratégico, definição visual \\ e gestão operacional eficaz \\ da parceria -, o shop-in-shop \\ influencia positivamente \\ a intenção de compra e a \\ imagem da marca.
}

No shop-in-shop, a empresa tem espaço claramente delimitado e diferenciado de sua marca no varejista, com autonomia total ou parcial sobre o sortimento ofertado, visual merchandising, preço, ativação de marketing, promoção, serviço e gestão de estoque. O objetivo é que o shop-in-shop reflita a imagem da marca e chame a atenção dos consumidores. Em contrapartida, o lojista recebe o aluguel pelo espaço concedido e, em alguns casos, um percentual sobre as vendas da marca. 


\section{VANTAGENS E RISCOS DO SHOP-IN-SHOP}

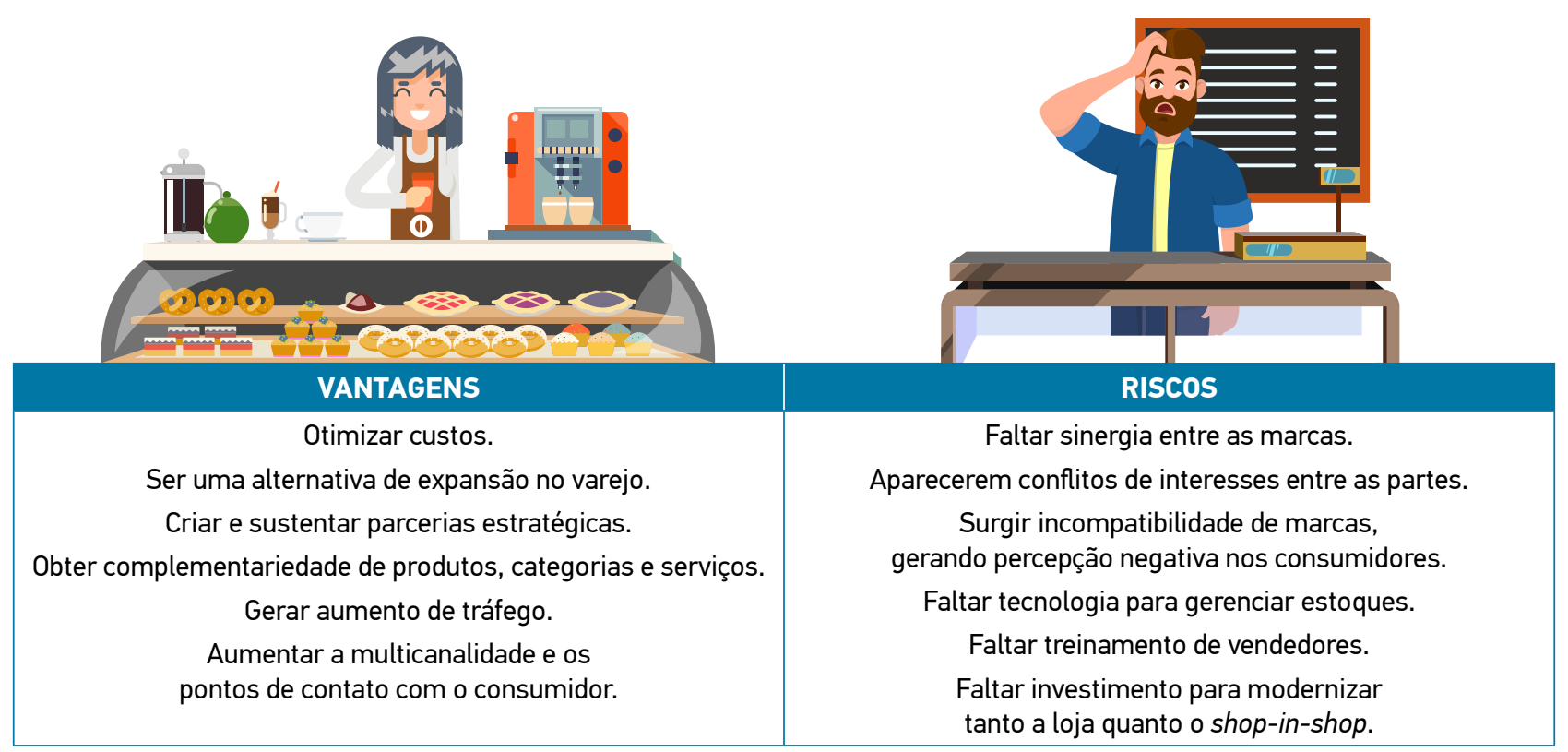

\section{BENEFÍCIOS}

Os estudos existentes sobre o tema destacam as vantagens do shop-in-shop. A primeira é, como já mencionado, financeira. Além da otimização de custos, a implementação do sistema não requer alto capital de investimento, em comparação ao de uma loja de marca própria ou mesmo ao de uma franquia. Como consequência, o shop-in-shop permite a expansão mais rápida de marcas do que os formatos tradicionais. Do ponto de vista da rede varejista que vai abrigar a marca, além de receber o aluguel e/ou a participação nas vendas, é possível delegar a gestão. Muitas vezes, faltam recursos, conhecimento e mesmo interesse do varejista para dar atenção aos diversos elementos da estratégia de cada marca.

A segunda vantagem refere-se ao shop-in-shop como uma estratégia de multicanal, aumentando os pontos de contato com os consumidores. No caso de fabricantes que desejam ingressar no varejo, de acordo com pesquisa da consultoria Ebeltoft Group, esse sistema ajuda a estabelecer interação direta com o consumidor, desenvolver canais de venda e melhorar a experiência do consumidor e o branding da marca. Pode ser até mesmo uma forma de teste antes de o fabricante partir para lojas próprias. Adicionado a isso, deve-se considerar um importante aspecto funcional, que trata da extensão da variedade de serviços que podem ser integrados ao espaço, gerando valor percebido ao cliente.
A terceira vantagem trata da complementaridade e sinergia entre as partes. Estudo de Karine Picot-Coupey, Jean-Laurent Viviani e Paul Amadieu publicado no International Journal of Retail \& Distribution Management mostra que, quando existe sinergia positiva, se podem observar maior eficiência do cross-selling das marcas e nível de serviço superior de uma ou mais categorias.

$\mathrm{Na}$ complementaridade e sinergia, pesam a reputação das partes, o norte estratégico, a definição visual e a gestão operacional da parceria. Estudo de Leandro Ulisses de Moraes para dissertação de mestrado, sob orientação de Benjamin Rosenthal, detectou influência positiva e significativa do shop-in-shop na intenção de compra e na imagem da marca Fila em lojas populares de calçados esportivos, sinalizando potenciais sinergias entre o fabricante e o varejista. Por meio de elementos de design e visual merchandising, o estudo demonstra que o sistema consegue criar um ambiente que influencia a percepção da imagem da marca por parte dos consumidores. Para o varejista, os cuidados da marca abrigada com a atmosfera do espaço (por elementos como layout, cores, olfato, música ambiente) ajudam a melhorar a própria imagem da rede, atraindo novos consumidores e customizando a experiência de compra.

\section{DESAFIOS}

Por outro lado, os estudos também mostram que a gestão desse tipo de sistema apresenta alguns desafios. O primei- 


\section{Se surgirem conflitos de interesses, os resultados serão insatisfatórios e começarão a aparecer na qualidade do atendimento, nos materiais de marketing e no sortimento ofertado.}

ro está relacionado a conflitos de interesses entre as partes, o que pode levar ao insucesso da parceria. As redes de varejo estão interessadas em aumentar as vendas do conjunto de produtos vendidos em suas lojas, seja ou não em sistema de shop-in-shop, e podem priorizar uma ou outra categoria ou marca, dependendo dos seus objetivos e perspectivas de ganhos. Já as empresas abrigadas querem promover apenas suas marcas e produtos.

De acordo com estudo de Kinshuk Jerath e Z. John Zhang publicado no Journal of Marketing Research, o sistema shop-in-shop costuma ser mais presente quando as lojas abrigadas são de marcas fortes e não facilmente substituíveis, ou seja, quando funcionam como um chamariz para o varejista, beneficiando suas vendas, e não são prejudicadas pela concorrência de outros produtos da rede.

O balanço no acordo e na gestão da parceria em busca de ganho para ambas as partes é o fundamento base para potencializar o resultado do shop-in-shop. Quando há um ruído nos interesses da relação, notam-se resultados insatisfatórios na qualidade do atendimento, nos materiais de marketing e no sortimento ofertado. Para evitar conflitos que coloquem a parceria em risco, o contrato precisa ser bem amarrado, definindo, por exemplo, quem pagará e supervisionará os funcionários alocados, quem fará a manutenção do espaço, como será realizada a definição de preços e promoções, em que medida serão permitidos competidores da marca nas lojas, como será definido o escopo de produtos a serem oferecidos e como será a gestão das informações dos clientes.

O segundo desafio aparece quando falta tecnologia eficiente para controlar e gerir os estoques nos espaços shop-in-shop. No mercado brasileiro, as tentativas de adoção desse sistema entre empresas esportivas e lojas de departamento na década de 1990 fracassaram por causa da falta de integração entre o sistema de gestão de estoque dos fabricantes com os varejistas. Frequentemente, os espaços destinados ao shop-in-shop ficavam com um mix reduzido de produ- tos ou eram abandonados pelos fabricantes, que terceirizavam a gestão para os varejistas. A inteligência no processo de logística e reposição do espaço, assim como o investimento no treinamento dos vendedores, é fundamento importante para o sucesso da estratégia.

O terceiro desafio é chegar a uma parceria estratégica que projete uma boa imagem para as partes. Pesquisa publicada no Journal of Retailing and Consumer Services mostra os riscos que surgem quando um varejista hospeda lojas de uma marca sem expressão ou quando uma marca com boa imagem monta espaço em um varejista com má reputação. A estratégia também tem de estar bem clara. Uma marca de luxo pode ter espaço em supermercados ou uma marca jovem estar presente em um varejista com público mais velho, caso seja bem trabalhado o objetivo de aumentar o público consumidor.

\section{CONCLUSÃO}

O shop-in-shop mostra-se como um sistema com potencial de benefícios tanto para redes de varejo quanto para fabricantes e outros varejistas, mas não é uma panaceia. Funciona apenas quando há alinhamento estratégico e ganhos sinérgicos e quando a gestão é muito bem planejada e executada.

\footnotetext{
PARA SABER MAIS:

- Abhijit Banerjee e Tanya Drollinger. Store within a store: matched versus mismatched image perceptions. Journal of Retailing and Consumer Services, v.36C, 2017. Disponivel em: doi.org/10.1016/j.retconser.2017.01.002

- Jia Li, Tat Chan e Michael Lewis. What happens when manufacturers perform the retailing functions? Production and Operations Management, v.25, n.8, 2016. Disponivel em: doi. org/10.1111/poms.12549

Karine Picot-Coupey, Jean-Laurent Viviani e Paul Amadieu. Determinants of retail store network expansion via shop-in-shops. International Journal of Retail \& Distribution Management, v.46, n.10, 2018. Disponivel em: doi.org/10.1108/JJRDM-08-2016-0139 - Kinshuk Jerath e Z. John Zhang. Store within a store. Journal of Marketing Research, v.47, n.4, 2010. Disponivel em: doi.org/10.150902Fjmkr.47.4.748

Steve Worthington. Shops within shops: a changing strategy for retailers. Retail and Distribution Management, v.12, n.6, 1984. Disponivel em: doi.org/10.1108/eb018250
}

LEANDRO ULISSES DE MORAES > Diretor de produtos e Mestre pelo Mestrado Profissional em Gestão para a Competitividade (MPGC) pela FGV EAESP > moraesleandro@hotmail.com

BENJAMIN ROSENTHAL > Professor da FGV EAESP > benjamin.rosenthal@fgv.br 